\title{
Performance-Based Seismic Design of Bridges: Challenges and Opportunities
}

\author{
Dr. A.H.M. Muntasir Billah, P.Eng \\ Assistant Professor, Department of Civil Engineering, \\ Lakehead University, Thunder Bay, ON, Canada
}

\begin{abstract}
Performance-based seismic design (PBSD) aims to dictate the structural performance in a predetermined fashion given the possible seismic hazard scenarios the structure is likely to experience. One major attributes of this PBSD is to keep bridges operational and reduce the repair cost by limiting the global and local deformations of a bridge to acceptable levels under design loads. While the concept of PBSD initiated several decades ago, its application in bridge design is still limited and evolving. Development and implementation of PBSD would allow bridge designers and owners to control the performance of a bridge in a preferred way during an earthquake. This presentation provides a summary of the current development in performance-based seismic design of bridges, compares the different design codes and guidelines, and identifies the current gaps and future opportunities. In addition, this presentation outlines a newly developed performance-based seismic design guideline for Shape Memory Alloy (SMA) reinforced concrete bridge pier.
\end{abstract}

